\title{
EXPERIMENTAL INVESTIGATION OF DUAL-PURPOSE SOLAR COLLECTOR USING WITH RECTANGULAR CHANNELS
}

\author{
H. Kavoosi Balotaki ${ }^{1, *}$, M.H. Saidi ${ }^{2}$ \\ Keywords: Solar Collector, Dual-purpose, Water Heater, Air Heater, Efficiency, Rectangular Channels
}

\begin{abstract}
Solar heat energy, one of the typical renewable energy absorbs radiation energy from the sun and converts it into heat energy. Since it is sustainable and eco-friendly, it can be a good alternative to solve the problem of the depletion of fossil fuels. But it has low density. So, solar collector is very important to use more efficiently. There are some possible approaches to scaling-up the effectiveness of a collector by re-thinking of using the collector as a heat exchanger. In the design of dual-purpose collector with rectangular fin (DPCRF), can be used for heating air and water simultaneously using incident solar radiation resulting in optimum usage of energy and space.
\end{abstract}

\section{INTRODUCTION}

Solar energy collectors are kind of heat exchangers which transforms solar energy flux to internal energy of the transport medium. The main component of any solar system is the solar collector. This is a device that absorbs the incoming solar radiation and converts it into heat. This heat transfers to working fluid flowing through the collector; such as air or water. Theoretical background of solar collectors and systems for energy absorption, efficiency and so forth are given in the fundamental books (Duffie and Beckman, 2005) [1] and (Chandraskar and Gkandpal, 2005) [2]. A survey of the various types of solar thermal collectors and applications is presented by Kalogirou [3]. Varury et al. [4] Studied on roughness geometry used in solar air heater. Ho et al. [5] performed the analysis of finned collector and collector with channel for drying applications. Khodadadi et al. [6] made an attempt to obtain a suitable design for the inlet and outlet positions of water in the reservoir of a solar collector. Azharul and Hawlader [7] investigated the evaluation of a V-groove solar collector. Chamoli et al. [8] had presented a review on the performance on double pass solar air heaters, These are solar water heating, which contain thermosyphon, integrated collector storage, direct and indirect systems and air systems, space heating and cooling, which includes air water systems and steam generation system, desalination, thermal power systems, which contain the parabolic trough, power tower and dish systems, solar furnaces, solar engine, solar heat pipe and many more applications to name. Other modeling studies in this field can be found in Refs. [9-12]. Investigation of the heat transfer performance of silver/water nanofluid in a solar flat-plate collector has been performed by Roy et al. [13]. Korti [14] applied numerical 3-D heat flow simulations to double-pass solar collector with and without porous media. Investigation of applications of nanotechnology to enhance the performance of the direct absorption solar collectors was performed by Hussein et al. [15]. The dual-purpose collector was first proposed by Kavoosi Balotaki et al. [16]. The present work is the design and study of a novel water and air heater as a single collector which is called dual-purpose solar collector with rectangular fin (DPCRF). The experimental results are shown in a case study for one of the city in Iran, Izeh.

\section{EXPERIMENTAL SETUP}

The DPCRF is a flat collector which is made of two sections, one for water heating and the other for air heating. The liquid collector section consists of parallel pipes and is connected to two main inlet and outlet ports for the reduction of pressure drop. The air heater section is designed to join the rectangular channels to the main absorber plate and the insulated plate at the bottom. This arrangement is shown in Fig.1 $(a, b)$. The collector is designed and made in a way that can be used for air and water heating simultaneously. The liquid section and air section are completely sealed and airtight against one another. 


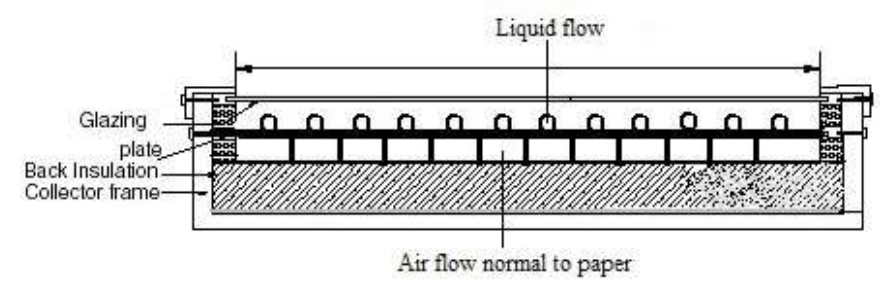

(a)

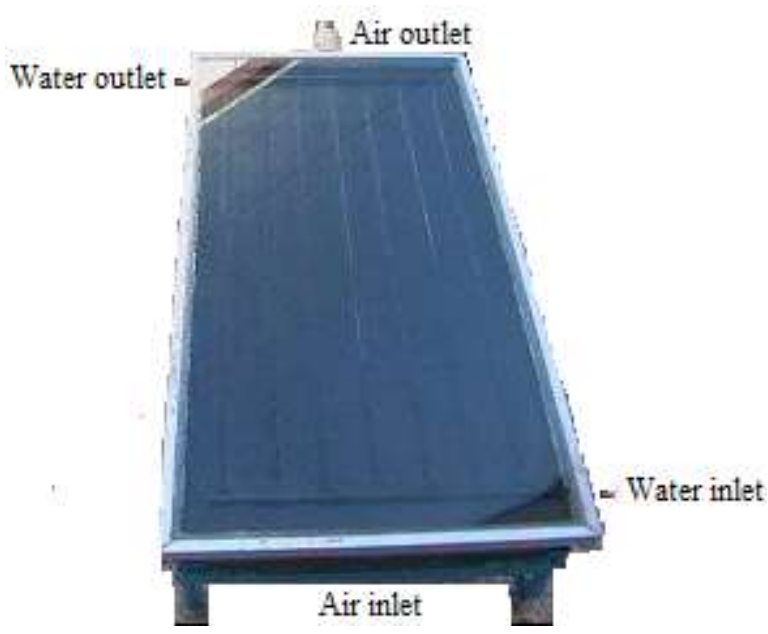

Figure 1. (a) Detail configuration of DPCRF (b) Dual-purpose collector with rectangular fin (DPCRF)

Detail specification of the designed collector is given as follows:

- Absorber material: black-painted aluminum sheet

- Form of air channel is rectangular.

- Air channel height: $6 \mathrm{~cm}$.

- Absorbent plate thickness: $1 \mathrm{~mm}$

- Side insulation: silicon rubber and polystyrene $(2 \mathrm{~cm})$

- Back insulation: fiberglass wool and polystyrene $(5 \mathrm{~cm})$

- Glazing: glass (thickness 6mm)

- No.of glazing: 1

- Air channel material: tinfoil sheet (thickness $0.5 \mathrm{~mm}$ )

- Collector mainframe material: Stainless Steel

- Dimension of absorber plate: $1.94 \mathrm{~m} \times 0.94 \mathrm{~m}$

- Collector tilt: $20^{\circ}$

Different tests for performance evaluation dual-purpose collector efficiency and reachable temperature limit in each one of systems of use of combined and separate are preformed according to the standard instructions which has been suggested by the American Association of thermal engineering (ASHRAE93-77,1977) [17]. The standard system collector efficiency measurement is as such that it will be exposed to the solar radiation and inlet and outlet temperature of fluid and volume of convection of fluid will be measured and then the amount of useful heat will be calculated as follow:

$Q_{u}=\dot{m} c_{p}\left(T_{o}-T_{i}\right)$

In addition to the above mentioned measurement, the amount of radiation, ambient temperature and wind speed will be registered. Therefore heat information and atmosphere's data will be available. In addition, the status of energy absorption and heat loss in the surrounding will be known to use ahead.

Various data have been obtained for each experiment by: 
- Measurement of flow rate, inlet and outlet temperature of fluid and atmosphere's data.

- Solar radiation measurement

Time constant of a collector is the required time for a collector fluid outlet temperature to reach 0.632 times final outlet temperature while the sun radiation on the collector is shut off. The total or main changes are happening in a fluid from the time of entering up to the time of constant time the way it's designed, the material used, type of fluid, fluid flow and working temperature. Therefore it can be measured in real operation time and should be less than 15 minutes for longer duration work ability and higher efficiency of collector. The time constant measurement of collector is done according to ASHRAE suggestion by using following equation:

$\frac{T_{o, t}-T_{i}}{T_{o, i}-T_{i}}$, here $\mathrm{T}_{o, \mathrm{i}}, \mathrm{T}_{\mathrm{o}, \mathrm{t}}$ are outlet fluid temperature in steady state time before shading and outlet fluid temperature in, t, time. Generally, the time for reaching the above quantity to 0.368 , is called time constant.

For this collector measured values are 4 and 7 minutes. for water and air respectively which is less than 15 minutes and it can be said, it is a suitable design.

\section{MATHEMATICAL MODELLING}

Analysis of combined dual-purpose collector with reference to Fig.1, indicates two parts, the liquid part (liquid collector), the air part with rectangular passage (air collector). Instantaneous thermal efficiency of a collector is expressed as Kutbas at al. [18] and Duffie et al. [1]:

$$
\eta_{i}=\frac{\dot{m} C_{P} \int_{t_{1}}^{t_{2}}\left(T_{o}-T_{i}\right) d t}{A \int_{t_{1}}^{t_{2}} I_{T} d t}
$$

Hence, the efficiency can be shown by following the relationship mentioned by Hottel-whillier-Bliss given as:

$\eta=\frac{Q_{u}}{A I_{T}}=F_{R}(\tau \alpha)-F_{R} U_{L} \frac{\left(T_{i}-T_{a}\right)}{I_{T}}$

where, $\mathrm{Qu}$ is the useful energy gain of collector, $(=0.85)$ is transmittance-absorptance product of cover system for beam and diffuse radiation, IT $=800 \mathrm{~W} / \mathrm{m} 2$ is the radiation on tilted surface. The heat removal factor FR of a solar collector is defined as the ratio of actual heat transfer to the maximum possible heat transfer and can be expressed as (Duffie et al, 2005):

$F_{R}=\frac{\dot{m} C_{P}}{A U_{L}}\left[1-e^{-\left(\frac{A U_{L} F^{\prime}}{\dot{m} C_{P}}\right)}\right]$

Here, $\dot{m}$ is the mass flow rate, $\mathrm{A}=1.94 \times 0.94 \mathrm{~m}^{2}$ area of collector, $\mathrm{C}_{\mathrm{P}}$ is the specific heat of fluid and $F^{\prime}$ $=0.94$ collector efficiency factor. To calculate the overall loss coefficient while using as fluid collector, one can use the equation which expressed as follows:

$U_{L}=U_{t}+U_{b}+U_{e}$

where, $\mathrm{U}_{\mathrm{L}}=4 \mathrm{~W} / \mathrm{m}^{2}{ }^{\circ} \mathrm{C}$ is overall loss coefficient and $\mathrm{U}_{\mathrm{t}}, \mathrm{U}_{\mathrm{b}}, \mathrm{U}_{\mathrm{e}}$ are top, back and lateral loss coefficient respectively.

Further, the temperature for the outlet liquid is (Duffie et al, 2005): 


$$
\frac{\left(T_{o}-T_{a}-\frac{S}{U_{L}}\right)}{\left(T_{i}-T_{a}-\frac{S}{U_{L}}\right)}=e^{-\left(\frac{A U_{L} F^{\prime}}{\dot{m} C_{P}}\right)}
$$

Here, $\mathrm{S}$ is absorbed solar energy per unit area and from this equation increase in temperature in outlet liquid from the liquid part can be obtained.

For obtaining the temperature increase we can use equations (2) and (3), which the result will be as follows (Azharul et al. [7]):

$$
\begin{aligned}
& \Delta T=\left(T_{o}-T_{i}\right)=\frac{F_{R} A(\tau \alpha) I_{T}}{\dot{m} C_{P}}-\frac{F_{R} A U_{L}\left(T_{i}-T_{a}\right)}{\dot{m} C_{P}} \\
& \Delta T=\left(T_{o}-T_{i}\right)=\frac{F_{R} A(\tau \alpha) I_{T}}{\dot{m} C_{P}}-\frac{F_{R} A(\tau \alpha) I_{t h}}{\dot{m} C_{P}}
\end{aligned}
$$

where

$$
I_{t h}=U_{L} \frac{\left(T_{i}-T_{a}\right)}{\tau \alpha}
$$

The heat transfer coefficient in the air section for the rectangular fin can be estimated by Eqs. (11) (Sukhatme [19]):

$$
N U=0.023 \operatorname{Re}_{D}^{0.8} \cdot \operatorname{Pr}^{0.4}
$$

where

$$
h_{a}=\frac{K_{a}}{D \times N U_{D}}
$$

This temperature rise equation is useful for the estimation of the temperature rise across the collector. The following relationship has been used for DPCRF:

$Q_{u}=\left(Q_{u}\right)_{L}+\left(Q_{u}\right)_{a}$

$\eta_{C}=\frac{Q_{u}}{A I_{T}}$

In this regard the indexes are for air and liquid part respectively. Of course here we should mention that the Eq. (13) is established as far as there is an increase in the temperature of both fluid.

\section{RESULTS AND DISCUSSION}

This section presents results of the DPCRF measured values and comparison with the estimated number using Eqs. [7, 8]. The tests were performed during months of June to August. The air and water mass flow rates are taken 0.01 and $0.11 \mathrm{~kg} / \mathrm{s}$, respectively in most of the experiments with $2 \%$ error. Figure 2 shows theoretical 
and experimental comparison for air collector efficiency and outlet temperature. Calculated results are in a good agreement with the experimental findings.

There is a difference between the experimental and theoretical results at low mass flow rates and natural convection in Fig. 2. This difference is due to the positive effect of the existence of connecting rivets in the air side on heat transfer which is not considered in the theoretical calculations.

Figure 3 shows the comparison of experimental variation for outlet air temperature for air heater collector in single use and with combined effect DPCRF. It is seen that the Dual-Purpose collector performs much better than stand alone system. Also Figure 3 shows that after $16 \mathrm{pm}$ the outlet air temperature in DPCRF increases due to water circulation at a temperature of $80^{\circ} \mathrm{C}$. This results in $21 \%$ increase compared to single usage. This characteristics of DPCRF may be well productive for solar systems that might work after sunset.

Figure 4 shows water outlet temperature at two cases. Figure 4 shows the comparison of the results of experimental variations of collector outlet water temperature for two cases, namely single usage and double purpose collector usage.

It is seen water outlet temperature is less affected with this design and slightly a higher temperature can be obtained with the DPCRF. The fluid temperature at the outlet of the water collector can be calculated by using equation 6. So, Table 1 shows theoretical and experimental comparison of water outlet temperature for various water flow rate of DPCRF. It is seen some agreement at lower flow rate.

Figure 5 indicates the decrease of liquid part efficiency with increase tank temperature and time. Also, one can see the efficiency variation in air at single or combined use. Here, the inlet air temperature is equal to ambient temperature.

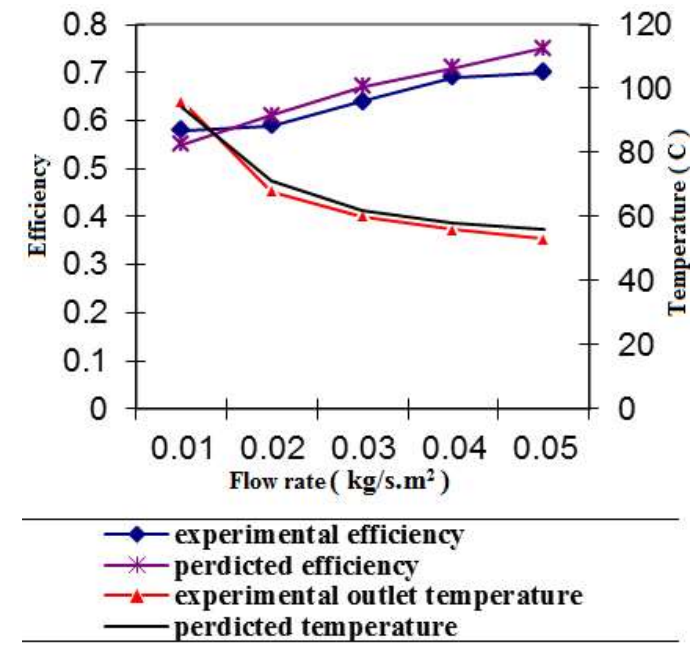

Figure 2. Experimental and theoretical of collector efficiency and outlet temperature.

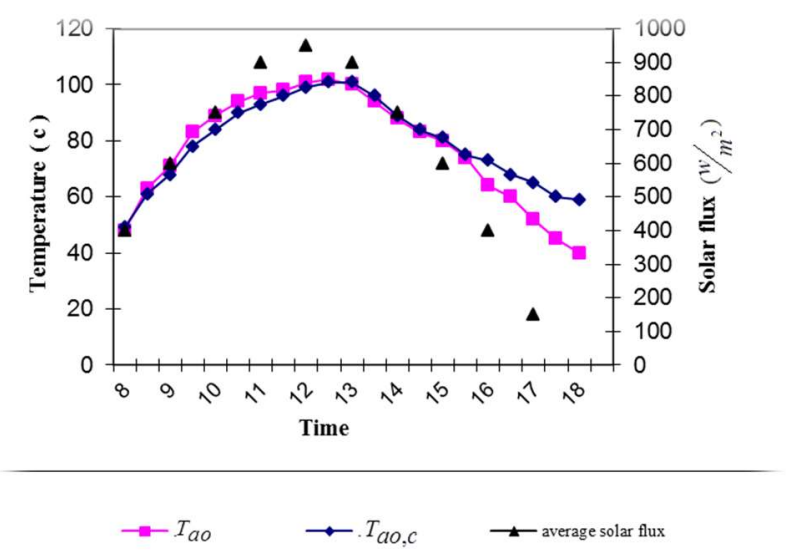

Figure 3. Experimental data on solar flux and outlet temperature of air at dual and single use condition 


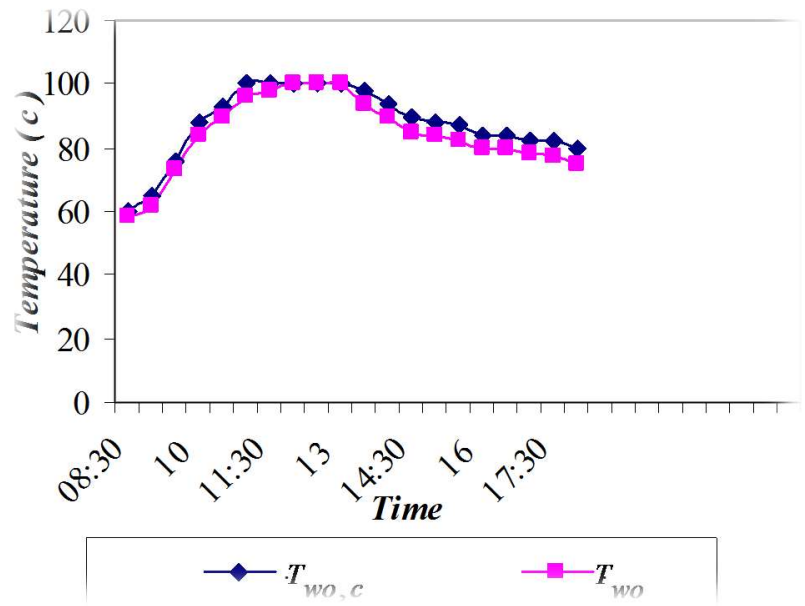

Figure 4. Experimental comparison of water outlet temperature for dual and single use condition of DPCRF with time at constant water flow rate

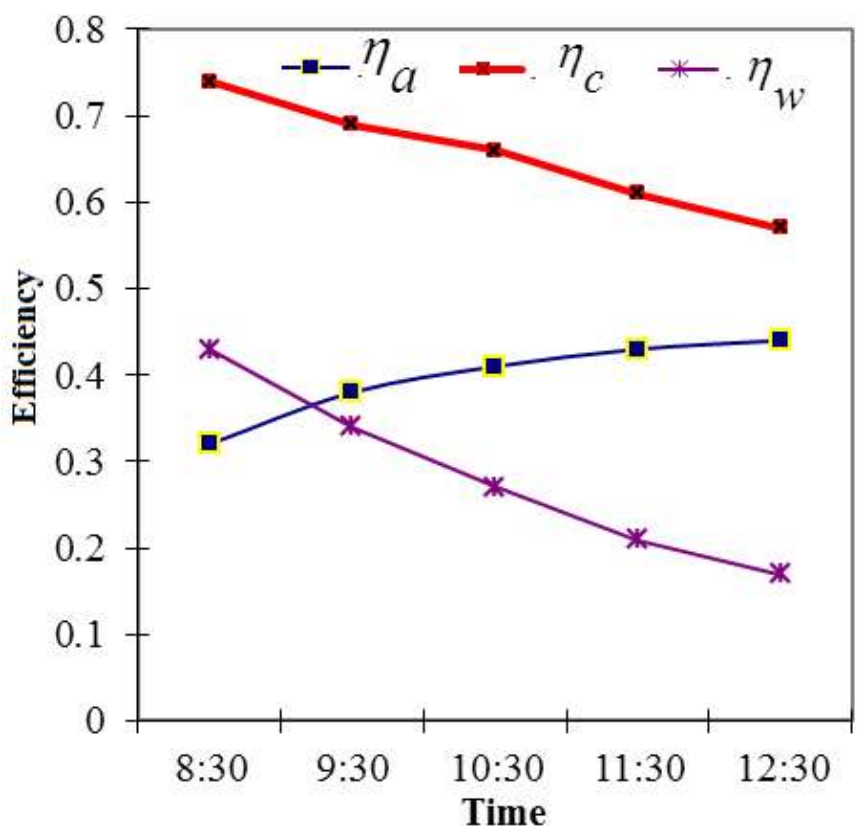

Figure 5. Comparison of efficiency between combined state in DPCRF and separate collectors

It seen that the collector efficiency in DPCRF is nearly $60 \%$. The liquid collector efficiency is about $20 \%$ because of increase in inlet liquid temperature.

So in dual purpose collector against the separate ready collector there are both of high temperature and efficiency. According to Eq.(3), one understands that a single usage collector can not reach high temperatures and high efficiencies simultaneously as with increase in the inlet temperature the loss will be increased and heat removal coefficient will be decreased. Figure10, showes this fact that the above mentiond problem may resolved by DPCRF.

Table 1. Experimental and theoretical comparison of water outlet temperature for various water flow rate

\begin{tabular}{|c|c|c|c|}
\hline$\dot{m}(\mathrm{~kg} / \mathrm{s})$ & $T_{i}\left(c^{\circ}\right)$ & $\begin{array}{c}\text { Experimental } \\
\text { water outlet } \\
\text { temperature } \\
\left(\mathbf{}^{\mathbf{}} \mathbf{C}\right)\end{array}$ & $\begin{array}{c}\text { Predicted } \\
\text { water outlet } \\
\text { temperature } \\
\left({ }^{\mathbf{}} \mathbf{C}\right)\end{array}$ \\
\hline 0.082 & 26 & 30 & 30.6 \\
\hline 0.043 & 26 & 33.5 & 44.8 \\
\hline
\end{tabular}




\section{CONCLUSION}

The main part of a solar system is the collector and in existing collectors such as flat plate, there is only one possibility of heat transfer to a fluid (liquid or air). DPCRF is designed and fabricated with the ability of heat transfer to two working fluids simultaneously and obtain desirable thermal energy from each one of fluids. The outlet temperature and efficiency are presented simultaneously with dual-purpose collector. The Dual-purpose collector in comparison to two single stage collector has the most useful heat. In the Dual-purpose collector in contrast to the stand alone collector with minimum flow rate for two fluid, there is chance of obtaining highest temperature and efficiency. The air part of dual-purpose collector with rectangular air channels which works as an air collector, there is about $11 \%$ increment in efficiency and outlet temperature in comparison with the other collectors such as V-corrugated and flat collectors. In the liquid collectors which are used in thermosyphon system increase inlet fluid temperature causes decrease in efficiency up to less than $20 \%$, but with referring to practical result obtained in the dual-purpose collector because of the maximum heat taken by air, there is a chance of efficiency up to $60 \%$ with minimum rate and maximum temperature of two fluid. Increase in fluid flow causes increase in efficiency, decrease in outlet temperature and decrease in heat loss. Increase in inlet fluid temperature into the collector compare to ambient temperature caused reduction in individual collectors efficiency. Comparison of data of experimental and theoretical outlet water temperature shows $4 \%$ error. The comparison results obtained by experimental and theoretical experiences for heat removal factor of fluid the error will be $3 \%$. In addition, the dual purpose collector with rectangular fin (DPCRF) there is a chance of reducing the expenses dramatically and space compared to the single collector.

\section{NOMENCLATURE}

$A_{c}$ Collector aperture area $\left(\mathrm{m}^{2}\right)$

$C_{p} \quad$ Specific heat of fluid $(j / k g k)$

$\mathrm{F}_{\mathrm{R}} \quad$ Collector heat removal factor

$I_{T} \quad$ Radiation on tilted surface $\left(\mathrm{W} / \mathrm{m}^{2}\right)$

$Q_{u} \quad$ Useful energy gain of collector $(W)$

$\mathrm{T}_{\mathrm{a}}$ Ambient temperature $\left({ }^{\circ} \mathrm{c}\right)$

$T_{i} \quad$ Inlet temperature $\left({ }^{\circ} \mathrm{c}\right)$

$T_{p} \quad$ Absorber plate temperature $\left(C^{\circ}\right)$

$\mathrm{T}_{\mathrm{ao}, \mathrm{c}}$ Outlet air temperature of DPCRF ( ${ }^{\circ} \mathrm{c}$ )

$\mathrm{T}_{\mathrm{ao}} \quad$ Outlet air temperature of separate air section $\left({ }^{\circ} \mathrm{c}\right)$

$\mathrm{T}_{\mathrm{wo}}$ Outlet water temperature of separate liquid section ( ${ }^{\circ} \mathrm{c}$ )

$\mathrm{T}_{\mathrm{wo}, \mathrm{c}}$ Outlet water temperature of DPCRF ( ${ }^{\circ} \mathrm{c}$ )

$U_{L} \quad$ Collector total loss coefficient $\left(\mathrm{W} / \mathrm{m}^{2} \mathrm{k}\right)$

$I_{t h} \quad$ Threshold radiation $\left(W / \mathrm{m}^{2}\right)$

$F^{\prime} \quad$ Collector efficiency factor

$\dot{m}$ Mass flow rate of fluid $(\mathrm{kg} / \mathrm{s})$

$\mathrm{Nu}$ Nusselt number

Pr Prandtl number

\section{Greek symbols}

$\eta_{\mathrm{C}} \quad$ Efficiency of DPCRF

$\eta_{\mathrm{w}} \quad$ Efficiency of separate water section of DPCRF

$\eta_{\mathrm{a}}$ Efficiency of separate air section of DPCRF

\section{REFERENCES}

[1] Duffie, J., and Beckman, W.A. 2005. "Solar energy thermal process". 3th ed. John Wiley. N.Y. 
[2] Chandraskar. B and Gkandpal. T, Solar hot water, heating and cooling systems. (2005) Texas Solar Energy Society.

[3] Kalogirou. S.A, Solar thermal collectors and applications. Progress in Energy and Combustion Science. 30 (2004) 231-295.

[4] Varury, Saini, R.P, Singal, S.K., 2007. A review on roughness geometry used in solar air heaters. J. Sol. Energy 81, 1340-1350.

[5] Ho, C.D., Yeh, H.M., Cheng, T.W., Chen, T.C., Wang, R.C., 2009. The Influences of recycle on performance of baffled double-pass flat plate solar air heaters with internal fins attached. J. Appl. Energy 86, 1470-1478.

[6] Khodadadi S, Ghanavati A, Assari MR, Hatami M, Experimental study on the water inlet and outlet position of a solar collector reservoir for maximum efficiency, Journal of Mechanical Science and Technology 29 (2015) 2279-2284.

[7] Azharul. M and Hawlader. A. Performance evaluation of a V-groove solar air collector. Applied Thermal Engineering 26 (2006) 121-130.

[8] Chamoli.S, R. Chauhan, N.S. Thakur, and J.S. Saini, 2012, A review of the performance of double pass solar air heater, Renewable and Sustainable Energy Reviews, Vol. 16, No. 1, pp. 481-492.

[9] Mohamadi ZM, Zohoor H (2011) Introducing a dimensionless number as tank selector in hybrid solar thermal energy storage systems, Journal of Mechanical Science and Technology, 25 (4) 871-876.

[10] Nguyen K.B, Yoon SH, Choi JH (2012) Effect of working- fluid filling ratio and cooling-water flow rate on the performance of solar collector with closed-loop oscillating heat pipe, Journal of Mechanical Science and Technology, 26 (1) 251-258.

[11] Seok I, Kim HJ, Byun G (2012) Structural optimization of a Cu (In, Ga) Se2 thin film solar cell using numerical simulation and design of experiment techniques, Journal of Mechanical Science and Technology, 26 (8) 2557-2563.

[12] Klein SA (1975) Calculation of flat plate collector loss coefficient. J. Sol. Energy 17, 79-80.

[13] Roy S., Asirvatham L. G., Kunhappan D., Cephas E., Wongwises S. Heat transfer performance of silver/water nanofluid in a solar flat-plate collector, Journal of Thermal Engineering 1(2015) 104-112.

[14] Korti A. L. N. Numerical 3-D heat flow simulations to double-pass solar collector with and without porous media, Journal of Thermal Engineering 1(2015) 10-23.

[15] Hussein A. K., Walunj A. A. Applications of nanotechnology to enhance the performance of the direct absorption solar collectors, Journal of Thermal Engineering 2 (2016) 529-540.

[16] Kavoosi.H, Assari, M.R, (2007).Design and performance of dual-purpose solar collector. In: Proceedings of 3rd International Energy, Exergy and Environment Symposium, IEEES-3, University of Evora. Portughal.

[17] ASHRAE. Standard 93-77 methods of testing to determine the thermal performance of solar collector. (1977) American Society of Heating, Refrigeration, and Air Conditioning Engineers. New York.

[18] Kutbas.I and Durmus.A, Efficiency and exergy analysis of a new solar air heater. Renewable Energy. 29 (2004) 1489-1501.

[19] Sukhatme, S.P., 1996. Solar Energy, second ed. McGraw- HILL, India. 